\title{
A novel, potentially targetable TMEM106B-BRAF fusion in pleomorphic xanthoastrocytoma
}

\author{
Susan J. Hsiao, ${ }^{1}$ Matthias A. Karajannis, ${ }^{2}$ Daniel Diolaiti, ${ }^{3}$ Mahesh M. Mansukhani, ${ }^{1}$ \\ Julia Glade Bender, ${ }^{4}$ Andrew L. Kung, ${ }^{3}$ and James H. Garvin, Jr. ${ }^{4}$ \\ ${ }^{1}$ Department of Pathology and Cell Biology, Columbia University Medical Center, New York, New York \\ 10032, USA; ${ }^{2}$ Department of Pediatrics, NYU Langone Medical Center, New York, New York 10016, USA; \\ ${ }^{3}$ Department of Pediatrics, Memorial Sloan Kettering Cancer Center, New York, New York 10065, USA; \\ ${ }^{4}$ Department of Pediatrics, Columbia University Medical Center, New York, New York 10032, USA
}

Abstract Pleomorphic xanthoastrocytoma (PXA) is a World Health Organization (WHO) Grade II glioma occurring primarily in children and young adults. Most PXAs harbor the known activating mutation BRAF V600E. We report a case of locally recurrent PXA with anaplastic features in a 10-yr-old female. The PXA was negative by immunohistochemical (IHC) staining for BRAF V600E mutation. Whole-exome and transcriptome sequencing of the tumor confirmed the absence of BRAF V600E, but identified copy-number alterations (including loss of the tumor suppressor CDKN2A) and a novel TMEM106B$B R A F$ fusion. Based on similar BRAF fusion proteins, this novel fusion is predicted to result in activation of BRAF signaling. Demonstration of positive IHC for phospho-ERK1/2 and phospho-MEK1/2 supported this prediction, and implicated MEK inhibitors as a potential therapeutic strategy.

Corresponding author: kunga@ mskcc.org

(c) 2017 Hsiao et al. This article is distributed under the terms of the Creative Commons Attribution-NonCommercial License, which permits reuse and redistribution, except for commercial purposes, provided that the original author and source are credited.

Ontology term: neoplasm of the central nervous system

Published by Cold Spring Harbor Laboratory Press

doi: $10.1101 / \mathrm{mcs} . \mathrm{a} 001396$

\section{CASE PRESENTATION}

This right-handed girl had onset of seizures at 2 years of age. Brain magnetic resonance imaging (MRI) was initially normal but was repeated at age 10 because of progressive headache and revealed a left temporal tip abnormality suggestive of ganglioglioma. She underwent resection of the lesion, which was reported as pleomorphic xanthoastrocytoma (PXA) with anaplastic features. Immunohistochemical (IHC) stain for BRAF V600E was negative. She remained seizure-free, but had local recurrence on MRI 6 months later, prompting re-resection. Pathology was identical, and IHC for BRAF V600E was again negative. She was referred for involved field radiation therapy, but following treatment had persistent tumor on MRI, with new contralateral disease, which was treated by stereotactic irradiation. Follow-up MRI showed further disease progression, and chemotherapy was initiated with temozolomide. Subsequent MRls have shown stable disease in response to temozolomide.

\section{METHODS}

Whole-exome and transcriptome sequencing was performed on DNA and RNA from blood and tumor (second surgery). Exome sequences were captured using Agilent SureSelect 
reagent V5+UTRs and sequenced on the Illumina HiSeq2500. An average coverage of 214- and 181-fold was obtained in the normal and tumor samples, respectively. Potential variants were filtered by known pathogenicity (ClinVar, Human Gene Mutation Database [HGMD], Online Mendelian Inheritance in Man [OMIM], Catalogue of Somatic Mutations in Cancer [COSMIC]) and frequency in the general population (The 1000 Genomes Project, Exome Variant Server, and our internal database). Copy-number changes were defined using EXCAVATOR software (Magi et al. 2013). Transcriptome sequencing was performed on RNA isolated from tumor. Transcriptome alignment was performed using the Tuxedo suite software package (Trapnell et al. 2012). One hundred and forty-eight million uniquely mapped reads were obtained. Translocations were detected using the FusionMap software. In view of BRAF V600E negativity, tumor was subjected to further IHC staining on formalin-fixed paraffin-embedded (FFPE) sections using standard procedures and the following antibodies: IgG control (sc-2027, Santa Cruz Biotechnology, Inc.), phospho-ERK1/2 (4370, Cell Signaling Technology), and phospho-MEK1/2 (2338, Cell Signaling Technology).

\section{Genomic Analysis}

A total of 124 somatic variants were identified and evaluated for pathogenicity and clinical significance. None were found to be clinically significant. Somatic copy-number changes identified included gain of Chromosome $7(1-159,138,663)$, loss of Chromosome 13 (1$115,169,878)$, and copy-number neutral loss of heterozygosity of 9p $(1-47,432,582)$ with copy-number loss of 9p21.3 (20,902,560-23,776,437, which includes the CDKN2A gene). Of note, transcriptome sequencing detected a novel TMEM106B-BRAF fusion on Chromosome 7, involving exons 1-3 of TMEM106B fused to exons 8-18 of BRAF (Fig. 1A; Table 1).

\section{Clinical Interpretation}

The primary treatment of PXA is surgical resection, and the outcome is generally favorable. Pathology is notable for anaplasia in $15 \%$ of PXAs, but there is no consensus regarding any advantage of adjuvant postsurgical therapy (Perkins et al. 2012). BRAF V600E mutation is found in nearly $70 \%$ of PXAs (Dias-Santagata et al. 2011). Activation of BRAF by chromosomal rearrangement, such as the KIAA1549-BRAF fusion, which is common in pilocytic astrocytomas, is rare in PXA (Antonelli et al. 2015). BRAF is a serine/threonine kinase downstream from RAS in the mitogen-activated protein kinase (MAPK) signaling pathway. Mutation in BRAF constitutively activates the RAS/RAF/MEK/ERK signaling pathway. The possibility of targeted therapy for BRAF V600E mutated PXA has now been realized, with the report of transient single-agent activity of the selective BRAF V600E inhibitor vemurafenib (Chamberlain 2013). TMEM106B functions in dendrite morphogenesis and maintenance by regulating lysosomal trafficking and may be associated with frontotemporal dementia. The TMEM106B-BRAF fusion in our case results in replacement of the amino-terminal regulatory domain of BRAF with the amino-terminal region of TMEMB106B while leaving the kinase domain of BRAF intact (Fig. 1B). Although not previously reported, this fusion is predicted to result in activation of BRAF signaling, based on the activity of similar BRAF fusion proteins. We used activation-state-specific immunohistochemical staining for phosphoERK1/2 and phospho-MEK to demonstrate activation of the MEK-ERK pathway downstream from BRAF signaling (Fig. 1C). Given reports showing that tumors harboring the KIAA1549BRAF fusion are not sensitive to vemurafenib and lead to paradoxical MEK-ERK activation, we expect PXA harboring TMEM106B-BRAF fusion will not be sensitive to vemurafenib as well, but could be sensitive to MEK inhibitors or second-generation RAF inhibitors such as PLX8394 (Sievert et al. 2013; Karajannis et al. 2014; Zhang et al. 2015). 


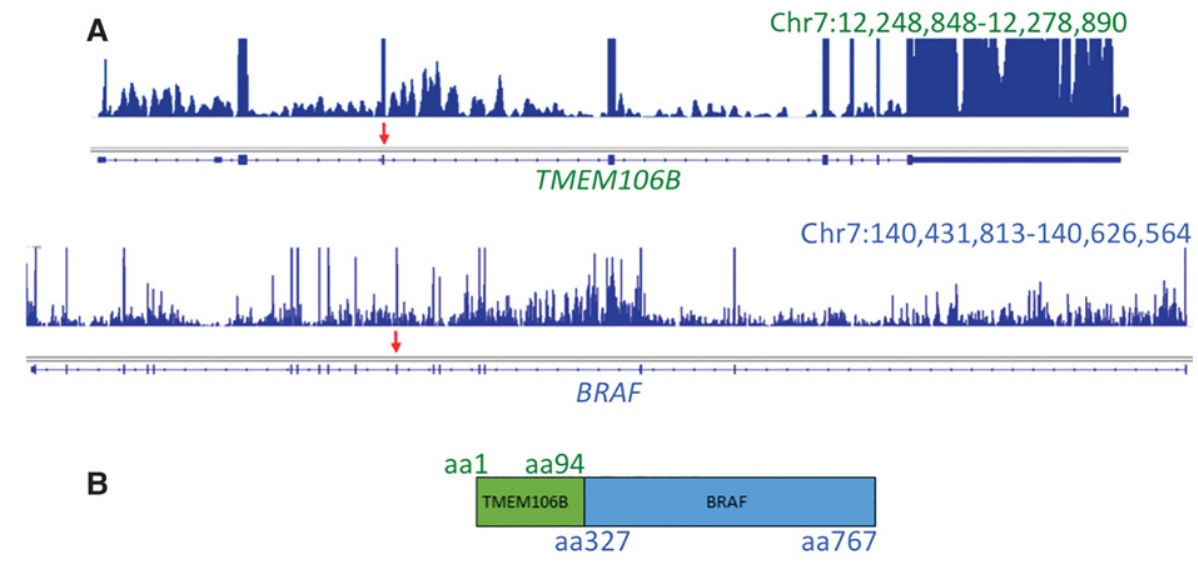

AGA TTA AGG CCA AGA AGA Acg CCC caa att ctc acc agt
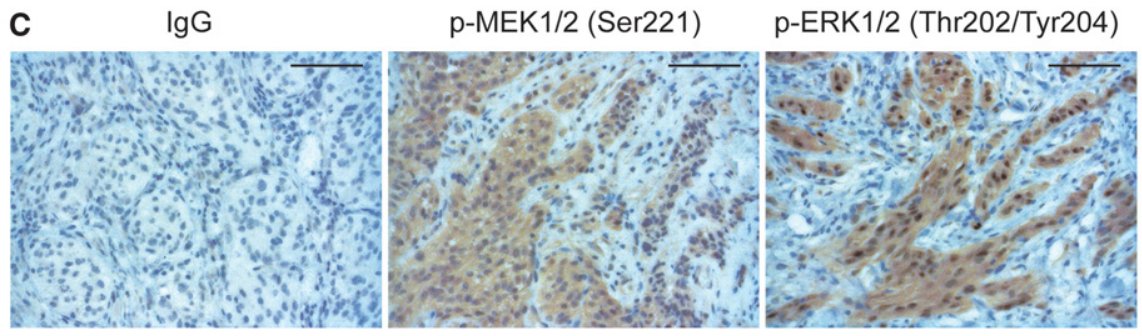

Figure 1. TMEM106B-BRAF activates MEK-ERK pathway. (A) Transcriptional readout of the TMEM106B and $B R A F$ loci from RNA-seq performed on primary tumor material. The site of translocation in each locus is indicated (red arrow). (B) Junctional sequence and reading frame. (C) Immunocytochemistry analysis of MEK/ERK pathway activity in patient's tumor utilizing phosphorylation-specific antibodies for phospho-MEK1/2 and phospho-ERK1/2. Scale bars, $100 \mu \mathrm{m}$.

\section{ADDITIONAL INFORMATION}

\section{Data Deposition and Access}

The data set supporting this article can be obtained from the cBioPortal for Cancer Genomics (http://cbioportal.org). The data set supporting the conclusions of this article can be obtained from the cBioPortal for Cancer Genomics (http://cbioportal.org) by selecting the DATA SETS tab and clicking on the citation listed in the Reference column. The

\begin{tabular}{|c|c|c|c|c|c|c|c|c|c|c|c|}
\hline Gene1 & Gene2 & Position 1 & Position 2 & Transcript 1 & $\begin{array}{c}\text { Exon } \\
\text { number } \\
1\end{array}$ & $\begin{array}{c}\text { Transcript } \\
\text { strand } 1\end{array}$ & Transcript 2 & $\begin{array}{c}\text { Exon } \\
\text { number } \\
2\end{array}$ & $\begin{array}{l}\text { Transcript } \\
\text { strand } 2\end{array}$ & $\begin{array}{l}\text { Fusion } \\
\text { junction } \\
\text { sequence }\end{array}$ & $\begin{array}{c}\text { Frameshift } \\
\text { class }\end{array}$ \\
\hline TMEM106B & BRAF & $\begin{array}{l}\text { Chr 7: } \\
\quad 12258147\end{array}$ & $\begin{array}{l}\text { Chr 7: } \\
\quad 140494267\end{array}$ & $\begin{array}{c}\text { NM_001134232_Chr7; } \\
\text { NM_018374_Chr7 }\end{array}$ & $3 ; 4$ & + & NM_004333_Chr7 & 8 & - & $\begin{array}{l}\text { TAGTGAT } \\
\text { CAGAGAT } \\
\text { TAAGGCC } \\
\text { AAGAAG } \\
\text { AACgCCCC } \\
\text { aaattctca } \\
\text { ccagtccgt } \\
\text { ctccttc }\end{array}$ & In-frame \\
\hline
\end{tabular}


Competing Interest Statement The authors have declared no competing interest.

Received August 22, 2016; accepted in revised form November 14, 2016 variant has been deposited in ClinVar (https://www.ncbi.nlm.nih.gov/clinvar/) under accession number SCV000328979.

\section{Ethics Statement}

Written patient consent was obtained for this clinical testing. Publication was approved by the Columbia University Medical Center Institutional Review Board (IRB\# AAAQ8170 and AAAP1200).

\section{Funding}

This work was supported by a grant from the Sohn Conference Foundation.

\section{REFERENCES}

Antonelli M, Badiali M, Moi L, Buttarelli FR, Baldi C, Massimino M, Sanson M, Giangaspero F. 2015. KIAA1549: $B R A F$ fusion gene in pediatric brain tumors of various histogenesis. Pediatr Blood Cancer 62: 724-727.

Chamberlain MC. 2013. Salvage therapy with BRAF inhibitors for recurrent pleomorphic xanthoastrocytoma: a retrospective case series. J Neurooncol 114: 237-240.

Dias-Santagata D, Lam Q, Vernovsky K, Vena N, Lennerz JK, Borger DR, Batchelor TT, Ligon KL, lafrate AJ, Ligon AH, et al. 2011. BRAF V600E mutations are common in pleomorphic xanthoastrocytoma: diagnostic and therapeutic implications. PLoS One 6: e17948.

Karajannis MA, Legault G, Fisher MJ, Milla SS, Cohen KJ, Wisoff JH, Harter DH, Goldberg JD, Hochman T, Merkelson A, et al. 2014. Phase II study of sorafenib in children with recurrent or progressive low-grade astrocytomas. Neuro Oncol 16: 1408-1416.

Magi A, Tattini L, Cifola I, D'Aurizio R, Benelli M, Mangano E, Battaglia C, Bonora E, Kurg A, Seri M, et al. 2013. EXCAVATOR: detecting copy number variants from whole-exome sequencing data. Genome Biol 14: R120.

Perkins SM, Mitra N, Fei W, Shinohara ET. 2012. Patterns of care and outcomes of patients with pleomorphic xanthoastrocytoma: a SEER analysis. J Neurooncol 110: 99-104.

Sievert AJ, Lang SS, Boucher KL, Madsen PJ, Slaunwhite E, Choudhari N, Kellet M, Storm PB, Resnick AC. 2013. Paradoxical activation and RAF inhibitor resistance of BRAF protein kinase fusions characterizing pediatric astrocytomas. Proc Natl Acad Sci 110: 5957-5962.

Trapnell C, Roberts A, Goff L, Pertea G, Kim D, Kelley DR, Pimentel H, Salzberg SL, Rinn JL, Pachter L. 2012. Differential gene and transcript expression analysis of RNA-seq experiments with TopHat and Cufflinks. Nat Protoc 7: 562-578.

Zhang C, Spevak W, Zhang Y, Burton EA, Ma Y, Habets G, Zhang J, Lin J, Ewing T, Matusow B, et al. 2015. RAF inhibitors that evade paradoxical MAPK pathway activation. Nature 526: 583-586. 


\section{COLD SPRING HARBOR Molecular Case Studies}

\section{A novel, potentially targetable TMEM106B-BRAF fusion in pleomorphic xanthoastrocytoma}

Susan J. Hsiao, Matthias A. Karajannis, Daniel Diolaiti, et al.

Cold Spring Harb Mol Case Stud 2017, 3: a001396 originally published online December 15, 2016 Access the most recent version at doi: $10.1101 / \mathrm{mcs} .0001396$

References This article cites 9 articles, 1 of which can be accessed free at: http://molecularcasestudies.cshlp.org/content/3/2/a001396.full.html\#ref-list-1

License This article is distributed under the terms of the Creative Commons Attribution-NonCommercial License, which permits reuse and redistribution, except for commercial purposes, provided that the original author and source are credited.

Email Alerting Receive free email alerts when new articles cite this article - sign up in the box at the Service top right corner of the article or click here. 